\title{
Increased oxidative stress in patients with familial Mediterranean fever during attack period
}

\author{
*Ediz L ${ }^{1}$, Ozkol H${ }^{2}$, Tekeoglu I ${ }^{1}$, Tuluce $\mathrm{Y}^{2}$, Gulcu E ${ }^{1}$, Koyuncu I ${ }^{3}$
}

1. Yuzuncu Yil University, Medical Faculty, Physical Medicine-Rehabilitation and Rheumatology Department, Van, Turkey

2. Yuzuncu Yil University, Medical Faculty, Department of Medical Biology, Van, Turkey

3. Harran University, Faculty of Science, Department of Biology, Sanliurfa, Turkey

\begin{abstract}
Objectives: We aimed to investigate the status of oxidant and antioxidants during attack period (AP) and attack free periods (AFP) in Familial Mediterranean fever (FMF) patients.

Methods: Measured the levels of malondialdehyde (MDA), protein carbonyl (PC), glutathione (GSH) and antioxidant vitamins (A,C and E) as well as the activities of catalase (CAT) and glutathione peroxidase (GSH-Px) in serum and whole blood of FMF patients in FMF-AP and FMF-AFP.

Results: Levels of MDA and PC were found significantly higher $(\mathrm{p}<0.05)$ both in serum and whole blood of FMF-AP group compared with other groups. The CAT and GSH-Px activities in FMF-AP group were found markedly lower (p $<0.05$ ) comparing to $\mathrm{HC}$ group. However, there were no statistically significant differences between the groups in terms of antioxidant vitamin levels.

Conclusions: Our study demonstrated increased oxidative stress in patients with FMF during AP. Investigations are needed to establish the effect of antioxidant supplementation on FMF attack frequency and severity. We also suggest that these increased MDA and PC levels and decreased antioxidants may be used as supportive markers to differentiate AP from AFP. These conclusions need to be validated in further multicenter studies with high number of FMF patients.
\end{abstract}

Key words: Antioxidant enzymes, Antioxidant vitamins, Familial Mediterranean fever, Lipid peroxidation, Protein oxidation African Health Sciences 2011; (S1): S6 - S13

\section{Introduction}

Inflammation is the physiological defence response of the organism to any kind of injurious stimulus. The migration of leucocytes to an injurious site results in phagocytosis of the pathogens or self-pathogens. Phagocytosis degree is correlated with the activation of reduced nicotinamide adenine dinucleotide phosphate (NADPH) oxidase and induction of oxygen uptake. The rapid uptake of oxygen and activation of NADPH oxidase initiate the generation of free radicals (FR) and reactive oxygen species (ROS). ${ }^{1}$ These FR or ROS can be defined as a chemical species, an atom or a molecule that has one or more unpaired electrons in its valance shell

\footnotetext{
*Corresponding author

Dr Levent Ediz

Yuzuncu Yil University Medical Faculty

Physical Medicine-Rehabilitation and

Rheumatology department

Arastirma Hastanesi, 65300

Van, Turkey

Telephone:+90 5079951732

E-mail: leventediz@gmail.com
}

which makes it unstable, short lived and highly reactive. Therefore, for gaining stability, it attacks the nearest stable molecule for stealing its electron. During inflammation condition in the tissue, the overproduction of FR/ROS occurs and this results in oxidative stress (OS) in the cells. ${ }^{1,2}$ The unsaturated fatty acids of the cell membrane are major targets for FR/ROS which result in disruption of membrane function. Lipid oxidation aspect of FR/ROS activity is detected by the measurement of lipid peroxidation (LPO) products such as malondialdehyde (MDA). 3,4 The oxidation of sulphydrils (thiols-SH) and the formation of carbonyl groups in proteins by FR/ ROS can also lead to deterioration of cell viability with loss of transport, enzyme and receptor functions. This protein oxidation aspect of FR/ROS activity is detected by the measurement of protein oxidation products such as protein carbonyl (PC) content. ${ }^{2-6}$

To overcome these toxic effects of OS, the tissues have both enzymatic and non-enzymatic mechanisms. ${ }^{7,8}$ While B-carotene, vitamin A, E, C, 
reduced glutathione (GSH), ubiquinone and flavonoids constitute common non-enzymatic antioxidants, superoxide dismutase (SOD), catalase (CAT) and glutathione peroxidase (GSH-Px) are the main enzymatic antioxidants in the body. ${ }^{8}$ Living human tissues continuously produce FR/ROS as part of metabolic processes. Under normal conditions, these FR/ROS are scavenged by the mentioned defense systems to maintain body homeostasis. However, under inflammatory or infectious conditions, FR/ROS productions exceed the eliminating capacity of the body antioxidant mechanisms, causing oxidation injury by attacking macromolecules like lipids, carbohydrates, proteins and nucleic acids. ${ }^{8}$

Familial Mediterranean fever (FMF) is an autosomal recessive, systemic relapsing autoinflammatory disorder seen in all populations but mainly mediterranean populations such as nonAshkenazi Jews, Arabs, Turks, and Armenians. ${ }^{9}$ This fever, which is also the most common disease of the hereditary periodic fevers, is characterized by fever and recurrent aseptic inflammation of serosal spaces. ${ }^{10}$ The most common clinical findings are peritonitis, articular complaints, and pleurisy accompanied by fever. Elevated erythrocyte sedimentation rate (ESR), white blood cell count (WBC), fibrinogen, and C-reactive protein (CRP) are seen during attack period (AP), but this usually returns to normal in attack-free periods (AFP)., ${ }^{9,10}$

However, if not treated with colchicine, a subclinic inflammation continues during the AFP and is related to increased serum amyloid A protein that leads to secondary amyloidosis and deposition of this insoluble protein in the kidney, liver, gut, bone marrow, spleen etc. As a result of this condition, before the clinical usage of colchicine, the development of renal failure was inevitable in a great deal of FMF patients by the mean age of $40 .{ }^{9,10}$

Pathologically, FMF attack is characterized by tissue infiltration by activated polymorphonuclear leukocytes (PMNL). The PMNL infiltration predominates in exudates recovered from peritoneal, pleural, or joint spaces at the time of acute attacks. Chemoattraction and phagocytosis may lead to FR/ ROS secretion ${ }^{9,10}$ and the excess of FR / ROS may be responsible for an OS state in FMF patients during AP.

Alteration in the oxidant-antioxidant profile is known to occur in rheumatic diseases. There have been studies in the literature on the possible role of $\mathrm{FR} / \mathrm{ROS}$ in the pathogenesis of some rheumatologic conditions such as rheumatoid arthritis (RA), Behcet's disease, systemic lupus erytemathosus etc ${ }^{11}$. To the best of our knowledge, the role of oxidants and antioxidant vitamins and enzymes during AP and AFP in FMF patients has not yet been assessed comprehensively. In the present trial, we aimed to investigate the levels of MDA, PC, GSH and antioxidant vitamins (A,C and $\mathrm{E}$ ) as well as the activities of CAT and GSH-Px in serum and whole blood of FMF patients during AP and AFP.

\section{Methods}

The study was conducted in Faculty of Medicine, Yuzuncu Yil University, Departments of Physical Medicine-Rehabilitation-Rheumatology and Medical Biology and Faculty of Science, Department of Biology during 2009 December-2010 September. A written consent to participate in the study was obtained from the subjects after they were thoroughly informed about the research details. Ethical approval for the study was obtained from the university ethic committee.

Patients fulfilling Tel Hashomer criteria were included in the study. ${ }^{12}$ All of the FMF patients were under treatment with Colchicine 1.5 gr daily. We divided all FMF subjects into FMF-AP and FMFAFP groups. All FMF patients and age/sex matched healthy controls (HC) were in age ranging from 20 to 40 years old. Patients with other inflammatory, autoimmune, acute or chronic infectious diseases and diabetes mellitus were excluded from the study. The HC group consisted of 31 individuals including 16 males and 15 females without a history of other potential health problems. The FMF-AP and FMFAFP groups were consisted of 40 patients including 19 males and 21 females and 34 patients including 18 males and 16 females respectively.

Totally, $7 \mathrm{ml}$ sample of venous blood was taken in the morning before breakfast from each patient who applied during AP or AFP to Physical Medicine-Rehabilitation and Rheumatology clinic. The blood samples of patients during FMF attack were obtained after 24-48 hours from the acute attack initiation. Venous blood was taken from HC, same as in FMF patients. Two $\mathrm{ml}$ of this venous blood was taken in tube with EDTA, and the rest in biochemical tube. Samples were kept in a cool box at $+4^{\circ} \mathrm{C}$ until they were transferred immediately to the laboratory. The serum samples were obtained by centrifuging blood samples at 3,000 rpm for 15 min at $4^{\circ} \mathrm{C}$. Afterwards serum samples were stored at $-20^{\circ} \mathrm{C}$ until analysis. 


\section{Oxidant/antioxidant status analysis}

Whole blood samples were hemolyzed with distilled water. The clear upper supernatant fluid was taken, and CAT, GSH-Px activities and the levels of GSH, MDA, PC and protein concentration were measured at this stage. These mentioned parameters and vitamin $\mathrm{A}$ (retinol), $\mathrm{C}$ and $\mathrm{E}$ ( $\alpha$-tocopherol) concentrations were also determined in serum.

\section{CAT (EC 1.11.1.6) activity determination}

The degradation speed of $\mathrm{H}_{2} \mathrm{O}_{2}$ by catalase was measured by reading the absorbance with a spectrophotometer (Genesys 10 UV Scanning UV/ VIS Spectrophotometer) set at $240 \mathrm{~nm}$ based on Aebi method. ${ }^{13}$

\section{GSH determination}

GSH concentration was assayed by reacting with Ophthaldialdehyde (OPT, $10 \mathrm{mg} / 10 \mathrm{ml}$ methanol) according to the modified method of Lee and Chung. ${ }^{14}$ Pure reduced GSH was used as standard for calibration. GSH samples were measured by using a spectrofluorimetry (Jasco 6000 USA) with excitation at $345 \mathrm{~nm}$ and emission at $425 \mathrm{~nm}$.

\section{Antioxidant vitamin determination}

All vitamin levels were measured spectrophotometrically (Genesys 10 UV Scanning UV/VIS Spectrophotometer). The levels of vitamin A (retinol) at $325 \mathrm{~nm}$ were detected after the reaction of serum: ethanol: hexane at the ratio of 1:1:3 respectively by Suzuki and Katoh. ${ }^{15}$ Serum vitamin C level was determined after derivatization with 2,4dinitrophenylhydrazine by Omaye et al. ${ }^{16}$ Vitamin $\mathrm{E}$ (a-tocopherol) was analyzed colorimetrically with 2,4,6-tripridyl-s-triazin and $\mathrm{FeCl}_{3}$ after the extraction with absolute ethanol and xylene by Martinek. ${ }^{17}$

\section{MDA determination}

To determine the amount of LPO in whole blood and serum, levels of MDA were analyzed spectrofluorimetrically, using the modified thiobarbituric acid-reactive substance (TBARS) method by Hegde et al. ${ }^{18}$ The MDA was measured by a spectrofluorimetry (Jasco 6000, USA), with excitation at $520 \mathrm{~nm}$ and emission at $555 \mathrm{~nm}$. Calculations were performed using a linear regression from tetraethoxypropane for the MDA standard curve.

\section{Protein carbonyl (PC) determination}

Protein oxidation was measured by Cayman's Protein Carbonyl Assay Kit (Cat. no 10005020) as carbonyl content in the samples. This kit bases on the principle which utilizes the DNPH reaction to measure the protein carbonyl content in samples ${ }^{19}$. The amount of protein-hydrozone produced is quantified spectrophotometrically at an absorbance $360 \mathrm{~nm}$ by $96-$ well plate reader (Spectra Max M5).

\section{Protein determination}

The protein content in the serum and whole blood were measured spectrophotometrically (Genesys 10 UV Scanning UV/VIS Spectrophotometer) by the method of Lowry et al. ${ }^{20}$ with bovine serum albumin as the standard.

\section{Measurement of acute-phase reactants}

C-reactive protein (CRP), Erthrocyte sedimentation rate (ESR), fibrinogen and white blood cell (WBC) count were measured on the same day of obtaining venous blood samples. Serum CRP level was determined by the nephelometric method (Beckman Array 360 Protein System, Minnesota, Brea, USA). The ESR was measured by Westergreen method, and ESR within one hour was recorded. Fibrinogen levels were measured by a photo-optical method in Amelung AMAX 190 Plus device (Taufkirchen, Germany). The total blood count including WBC was measured by STKS autoanalyzer (Hialeah, Finland).

\section{Statistical analysis}

The results were analyzed using one way analysis of variance (ANOVA) test. The level of statistical significance was set at $\mathrm{p}<0.05$. Spearman's correlation coefficient was used to assess correlations. Results were presented as means \pm standard deviation (SD). SPSS package version 13 was used for analysis.

\section{Results}

The mean age of FMF subjects in FMF-AP and FMF-AFP groups were $26.3 \pm 6.4$ and $27.4 \pm 7.2$ years respectively while the mean age of $\mathrm{HC}$ group was $27.2 \pm 7.9$ years. The disease durations were $6.1 \pm 4.2$ and 5.2 \pm 3.6 years for FMF-AFP and FMF-AP groups respectively. The groups were similar in terms of age and gender (Table 1). 
Table 1: Demographic characteristics of study groups

$\begin{array}{lcclc}\begin{array}{l}\text { Feature } \\ \text { Age (years) }\end{array} & \text { HCn=31 } & \text { FMF-AP } \mathbf{n = 4 0} & \text { FMF-AFP } \mathbf{n = 3 4} & \text { P value } \\ \begin{array}{l}\text { Gender } \\ \text { Female/male }\end{array} & 27.2 \pm 7.9 & 26.3 \pm 6.4 & 27.4 \pm 7.2 & \text { NS } \\ \begin{array}{l}\text { Duration of } \\ \text { disease (years) }\end{array} & 15 / 16^{*} & 16 / 18^{*} & 21 / 19^{*} & \text { NS } \\ * \text { Chi-squre test was used, NS: Nonsignificant } & & 9.1 \pm 7.5 \pm 6.3 & \text { NS }\end{array}$

The levels of acute-phase reactants of FMF patients were shown in Table 2. The ESR, CRP and fibrinogen levels were significantly higher in FMF-AP than FMF-AFP and HC groups $(\mathrm{p}<0.001)$.

Table 2: Acute phase reactants of the groups

\begin{tabular}{llll}
\hline & $\begin{array}{l}\text { HC } \mathbf{n}=31 \\
(\text { mean } \pm \text { SD })\end{array}$ & $\begin{array}{c}\text { FMF-AP } \mathbf{n}=40 \\
(\text { mean } \pm \text { SD })\end{array}$ & $\begin{array}{l}\text { FMF- AFP } \mathbf{n}=34 \\
(\text { mean } \pm \text { SD })\end{array}$ \\
\hline ESR $(\mathrm{mm} / \mathrm{h})$ & $10.4 \pm 7.8$ & $30.1 \pm 22.6^{\mathrm{a}}$ & $12.8 \pm 8.7^{\mathrm{b}}$ \\
$\mathrm{CRP}(\mathrm{mg} / \mathrm{l})$ & $1.4 \pm 3.4$ & $5.3 \pm 6.1^{\mathrm{a}}$ & $1.5 \pm 3.8^{\mathrm{b}}$ \\
WBC $(/ \mathrm{mm} 3)$ & $7570 \pm 3840$ & $9130 \pm 5120$ & $7740 \pm 3660$ \\
Fibrinogen & & & \\
$(\mathrm{mg} / \mathrm{dl})$ & $289.8 \pm 82.9$ & $474.2 \pm 165.4^{\mathrm{a}}$ & $295.7 \pm 77.3^{\mathrm{b}}$ \\
\hline
\end{tabular}

SD - Standard deviation

${ }^{a}$ Significantly different from $\mathrm{HC}$ at $p<0.05$ level,

bignificantly different from FMF-AP at $p<0.05$ level

Serum oxidant and antioxidant levels of the study groups are presented in Table 3. The MDA and PC levels were found significantly higher $(\mathrm{P}<0.05)$ in FMF-AP group comparing to FMF-AFP and HC.
However, there were no statistically significant differences between the groups in terms of GSH and antioxidant vitamin levels as well as CAT and GSH-Px activities.

Table 3: Serum oxidant/antioxidant status in patients with FMF and HC

\begin{tabular}{llll}
\hline Oxidant/antioxidant & HC (mean \pm SD) & FMF-AP (mean \pm SD) & FMF-AFP (mean \pm SD) \\
\hline CAT k/g protein & $1,09 \pm 0.28$ & $0.98 \pm 0.36$ & $1,05 \pm 0,33$ \\
GSH-Px U/g protein & $1,21 \pm 0,28$ & $1,12 \pm 0,18$ & $1,16 \pm 0,14$ \\
GSH $\mu \mathrm{mol} / \mathrm{ml}$ & $0.12 \pm 0.01$ & $0.11 \pm 0.01$ & $0,12 \pm 0,01$ \\
$\mathrm{MDA} \mu \mathrm{mol} / \mathrm{L}$ & $1.56 \pm 0.14$ & $2.13 \pm 0.43^{\mathrm{a}}$ & $1,58 \pm 0,36^{\mathrm{b}}$ \\
$\mathrm{PC} \mathrm{nmol} / \mathrm{mg} \mathrm{protein}$ & $2.43 \pm 0.48$ & $3.66 \pm 0.93^{\mathrm{a}}$ & $2,44 \pm 0,59^{\mathrm{b}}$ \\
Vitamin A $\mu \mathrm{g} / \mathrm{dl}$ & $55.76 \pm 15.01$ & $52.78 \pm 12.79$ & $53,39 \pm 11,41$ \\
Vitamin C mg/dl & $0.70 \pm 0.18$ & $0.70 \pm 0.18$ & $0,72 \pm 0,08$ \\
Vitamin E mg/dl & $1.17 \pm 0.19$ & $1.14 \pm 0.21$ & $1,07 \pm 0,11$ \\
\hline
\end{tabular}

SD - Standard deviation

aSignificantly different from $\mathrm{HC}$ at $p<0.05$ level,

bSignificantly different from FMF-AP at $p<0.05$ level

Whole blood oxidant/antioxidant status of the study groups are presented in Table 4. Significantly higher MDA, PC levels and lower GSH-Px, CAT activities as well as GSH levels were found in FMF-AP group comparing to FMF-AFP and HC groups $(\mathrm{P}<0.05)$. In FMF-AP group, significant correlations were found between serum and whole blood MDA, PC levels and acute phase reactant CRP $(r=0.21$ $\mathrm{p}=0.024 ; \mathrm{r}=0.19-\mathrm{p}=0.031$ and $\mathrm{r}=0.27-\mathrm{p}=0.018$; $\mathrm{r}=0.21-\mathrm{p}=0.028)$ respectively. There were no significant correlations between serum and whole blood oxidant/antioxidant parameters and the other acute phase reactants in all groups. 
Table 4: Whole blood oxidant/antioxidant status in patients with FMF and HC

\begin{tabular}{llll}
\hline Oxidant/antioxidant & HC (mean \pm SD) & FMF-AP (mean \pm SD) & FMF-AFP (mean \pm SD) \\
\hline CAT k/g Hb & $63.92 \pm 12.70$ & $49.17 \pm 13.08^{\mathrm{a}}$ & $57.60 \pm 17.86$ \\
GSH-Px U/g Hb & $12,32 \pm 1,07$ & $10.84 \pm 1.21^{\mathrm{a}}$ & $11.53 \pm 2.53$ \\
GSH $\mu \mathrm{mol} / \mathrm{ml}$ & $0.92 \pm 0.24$ & $0.56 \pm 0.12^{\mathrm{a}}$ & $0.91 \pm 0.12^{\mathrm{b}}$ \\
$\mathrm{MDA} \mu \mathrm{mol} / \mathrm{L}$ & $5.46 \pm 0.71$ & $7.17 \pm 1.79^{\mathrm{a}}$ & $5.59 \pm 1.82^{\mathrm{b}}$ \\
PC $\mathrm{nmol} / \mathrm{mg}$ protein & $29.32 \pm 6.94$ & $39.44 \pm 12.80^{\mathrm{a}}$ & $29.89 \pm 6.59^{\mathrm{b}}$ \\
\hline
\end{tabular}

SD - Standard deviation

${ }^{a}$ Significantly different from $\mathrm{HC}$ at $p<0.05$ level

bignificantly different from FMF-AP at $p<0.05$ level

\section{Discussion}

An inflammatory process is the main pathology in FMF but the factors that affect inflammation in FMF attack and AFP are still being investigated. In this current trial, we determined an increased OS state in FMF-AP group. This condition may be attributed to inflammatory processes during AP. There are conflicting data in the literature about oxidant/ antioxidant status in rheumatologic diseases such as RA and Behcet disease. In previous studies, fluctuated or unchanged oxidant/antioxidant status was detected in RA and Behcet patients. ${ }^{21-26}$

The LPO and protein oxidation is a part of normal metabolism and elevations in these processes occur when the dynamic balance between oxidant and antioxidant mechanisms is impaired. Measurement of the cellular membrane lipid breakdown products such as MDA is the most common approach to determine the degree of LPO induced by FR/ROS. Furthermore, PC is the most commonly used biomarker of oxidative protein damage, being considered an early marker of protein oxidation. ${ }^{4-6}$ Increased MDA and PC levels in the serum and whole blood of patients with acute FMF attack confirm the presence of increased OS in FMF patients during attack period. It is likely that increased serum or whole blood MDA and PC levels might indirectly show increased PMNL activation and phagocytosis during FMF attack. Moreover, to our opinion these parameters may be used as supportive markers to differentiate FMF attacks from AFP.

Our results also suggest that a low-grade inflammation coexists in these patients just before the FMF attack, because after the initiation of inflammation, approximately $24-48$ hours is required to detect OS markers in the circulation. ${ }^{27} \mathrm{We}$ measured OS markers after 24-48 hours from the initiation of acute FMF attack. In a previous study, slightly increased plasma LPO products were found in attack free FMF patients. ${ }^{28}$ Sarkisian et al. ${ }^{29}$ found in 20 adult FMF-AFP patients that the $\mathrm{O}_{2}$ production by patient PMNL was higher than that of control PMNL and the $\mathrm{O}_{2}^{-}$production by PMNL from patients with amyloidosis was not different from that of patients without amyloidosis. ${ }^{29}$ Kirkali et al. ${ }^{30}$ showed the accumulation of some major products of oxidative damage to DNA in PMNL of 17 FMF-AFP patients. In our study, patients included to FMF-AFP group were selected from those who were within AFP for at least 2 months, thus we didn't detect OS in these patients.

The GSH is one of the most important endogenous antioxidants and provides a sulfhydryl $(\mathrm{SH})$ group for direct scavenging reactions by GST and GSH-Px. It also plays roles a scavenger of vitamins $C$ and $E$ radicals. ${ }^{31,32}$ In this study decreased GSH level in FMF-AP may be associated to its exhaustion in the course of increased OS. It is thought that OS is a mechanism of molecular and cellular damage in a wide spectrum of diseases. ${ }^{33}$ The literature about OS in FMF is very sparse. We could find only a few trials in the literature which evaluate increased LPO products in FMF. ${ }^{28-30}$ Results of the previous studies about OS in the other inflammatory rheumatic diseases such as RA and Behcet's disease are very concordant concerning our findings in FMF. Furthermore, MDA and/or PC levels were significantly higher in circulation of active Behcet patients and RA than that of control subjects. ${ }^{34-38}$ Consistent with previous studies in active Behcet patients and RA, ${ }^{34,37,38}$ our results showed that MDA and PC levels in FMF-AP were linked to the disease activity markers such as acute phase reactant CRP.

Free radical-scavenging enzymes such as GST, CAT and GSH-Px are the first line of cellular defense against oxidative injury. We have observed decreased activities of GSH-Px and CAT in whole blood of FMF patients in acute attack. It is known 
that GST and GSH-Px scavenge $\mathrm{H}_{2} \mathrm{O}_{2}$ in the presence of GSH. The CAT converts $\mathrm{H}_{2} \mathrm{O}_{2}$ into $\mathrm{H}_{2} \mathrm{O}$ and $\mathrm{O}_{2}$ without GSH. In this study, the decrease in whole blood GSH-Px and CAT activities may be due to inactivation of the enzymes by excess $\mathrm{H}_{2} \mathrm{O}_{2}$ formed. Additionally the low GSH-Px activity may be explained by the low GSH level found in FMFAP patients because GSH is a substrate and co-factor of this enzyme. We didn't find significant decrease of these enzymes in serum because their lower serum activities are less sensitive to alterations than that in whole blood. Related to GSH defence system and antioxidant enzymes in the literature; similar to our data in FMF-AP patients, significantly low GSH level and GSH-Px and CAT activities were observed in active Behcet and RA patients. ${ }^{39-43}$ Gurbuz et al. ${ }^{44}$ also investigated OS in FMF with $(n=21)$ or without proteinuria $(\mathrm{n}=23)$. In their study, although decreased plasma GSH-Px activities were not different from each other between proteinuric and nonproteinuric FMF patients, significantly higher plasma MDA levels in proteinuric FMF patients were detected.

In this study, we also evaluated and compared antioxidant vitamin levels in FMF-AFP and FMF-AP groups. These antioxidant vitamins increase the overall antioxidant capacity and decrease the oxidative damage occurring in tissues. B-carotene is a precursor of vitamin A. B-carotene is a chainbreaking lipid-soluble antioxidant which inhibits LPO initiated by xanthine oxidase and traps the peroxyl radicals. ${ }^{45}$

In a study, plasma $\mathrm{B}$-carotene concentrations in patients with RA were lower compared with controls. ${ }^{46}$ Vitamin E has a strong antioxidant capacity, antiinflammatory activity, and also plays a major role in maintaining integrity of cell membranes by limiting LPO. ${ }^{47}$ Low antioxidant vitamin level (alphatocopherol, B-carotene and selenium) was a risk factor for RA. ${ }^{48}$ In a mouse model for RA, animals fed omega-3 and additional vitamin E-enriched diet showed significantly lower serum TNF-Alpha, IL6, PGE2, and LTB4 levels compared with the omega-3 diet alone. ${ }^{49}$ Vitamin $\mathrm{C}$ which is the major water-soluble antioxidant vitamin plays an important role in mechanisms involved in immune function and inflammatory processes and prevents oxidative modification of LDL by scavenging free radicals and other ROS. Additionally, it preserves vitamin $\mathrm{E}$ and $\mathrm{B}$-carotene levels during OS. ${ }^{11}$ We did not find any differences in serum levels of antioxidant vitamins between HC and FMF-AP and FMF-AFP groups.
To our knowledge this is the first trial in the literature evaluating antioxidant vitamin levels in FMF patients. At present, FMF is routinely treated with colchicine. However, colchicine can only reduce the frequency of the attacks, but is without effect during the attacks. As the current trial demonstrated increased OS state in patients with FMF during AP, and because of the involvement of active oxygen species in the disease process in previous studies, we suggest that further investigations are needed to establish the effect of antioxidants and free radical scavengers supplementation on FMF attack severity. For instance, Sahin M. et al..$^{50}$ found that colchicine induced protective effects on oxidative stress by modulating vitamin $\mathrm{E}, \mathrm{B}$-carotene and $\mathrm{Ca}^{2}+$-release levels in FMF patients with a remission period.

\section{Limitations of the study}

The sample size was small and the patients who underwent FMF attack in the last two months were not included in the study as a separate group.

\section{Conclusion}

In the current study, FMF patients in AP had lower GSH level as well as GSH-Px and CAT activities in whole blood and higher MDA and PC levels both in serum and whole blood compared to FMF-AFP and $\mathrm{HC}$ groups. We did not find any differences in serum levels of antioxidant vitamins between groups. Since our study demonstrated increased OS state in patients with FMF during AP, we suggest that investigations are needed to establish the effect of antioxidant supplementation on FMF attack frequency and severity. Also, in our opinion, these increased LPO and protein oxidation end products and decreased antioxidants may be used as supportive markers to differentiate FMF attacks from AFP. These conclusions need to be validated in further multicenter studies with high number of FMF patients.

\section{References}

1. Roberts RA, Smith RA, Safe S, Szabo C, Tjalkens RB, Robertson FM, et al. Toxicological and pathophysiological roles of reactive oxygen and nitrogen species. Toxicology. 2010; 276(2):85-94.

2. Valko M, Leibfritz D, Moncol J, Cronin MT, Mazur M, Telser J, et al. Free radicals and antioxidants in normal physiological functions and human disease. Int J Biochem Cell Biol. 2007; 39(1):44-84. 
3. Therond P, Bonnefont-Rousselot D, Davit-Spraul A, Conti M, Legrand A. Biomarkers of oxidative stress: an analytical approach. Curr Opin Clin NutrMetab Care. 2000; 3(5):373-84.

4. Dalle-Donne I, Rossi R, Giustarini D. Protein carbonyl groups as biomarkers of oxidative stress. Clin Cbim Acta. 2003; 329:23-38.

5. Brown-Galatola CH, Hall ND. Impaired suppressor cell activity due to surface sulphydryl oxidation in rheumatoid arthritis. BrJ Rheumatol 1992; 31:599-603.

6. Urso ML, Clarkson PM. Oxidative stress, exercise, and antioxidant supplementation. Toxicology. 2003;189:4154.

7. Sies H. Oxidative stress: oxidants and antioxidants. Exp Physiol. 1997; 82:291-95.

8. Kohen R, Nyska A. Oxidation of biological systems: oxidative stress phenomena, antioxidants, redox reactions, and methods for their quantification. Toxicol Pathol. 2002; 30:620-50.

9. Ben-Chetrit E, Touitou I. Familial Mediterranean fever in the world. Artbritis Rheum. 2009; 61:1447-53.

10. Chae JJ, Aksentijevich I, Kastner DL. Advances in the understanding of familial Mediterranean fever and possibilities for targeted therapy. Br J Haematol. 2009; 146:467-78.

11. Calder PC, Albers R, Antoine JM, Blum S, BourdetSicard R, Ferns GA, et al. Inflammatory disease processes and interactions with nutrition. BrJ Nutr. 2009; 101:145.

12. Livneh A, Langevitz P, Zemer D, Zaks N, Kees S, Lidar $\mathrm{T}$, et al. Criteria for the diagnosis of familial Mediterranean fever. Artbritis Rheum. 1997; 40:1879-85.

13. Aebi H. Catalase. In: HU Bergmeyer (ed). Methods of enzymatic analysis, Academic Press, New York, 1974; 673-77.

14. Lee AYW, Chung SSM. Contributions of polyol pathway to oxidative stress in diabetic cataract. The Federation of American Societies for Experimental Biology Journal. 1999; 13:23-30.

15. Suzuki I, Katoh NA. Simple and cheap methods for measuring serum vitamin $A$ in cattle using spectrophotometer. Japanese journal of veterinary science. 1990; 52:1281-83.

16. Omaye ST, Turnbul JD, Savberlich HE. Ascorbic acid analysis. II. Determination after derivatisation with 2.2. dinitrophenylhydrazine. Selected methods for determination of ascorbic acid in animal cells, tissues and fluids. Methods in Ensymology. 1979; 62:67.

17. Martinek R. Method for determination of vitamin E (total tocopherol) in serum. Clinical Chemistry. 1964;10:1078-86.

18. Hegde KR, Henein MG, Varma SD. Establishment of mouse as an animal model for study of diabetic cataracts: biochemical studies. Diabetes, Obesity and Metabolism. 2003; 5:113-9.
19. Levine RL, Garland D, Oliver CN. Determination of carbonyl content in oxidatively modified proteins. Methods in Ensymology. 1990; 186:464-78.

20. Lowry OH, Rosebrough NJ, Farr AL. Protein measurement with the folin phenol reagent. Journal of Biological Chemistry. 1951; 193:265-75.

21. De Leo ME, Tranghese A, Passantino M. Manganese superoxide dismutase, glutathione peroxidase, and total radical trapping antioxidant capacity in active rheumatoid arthritis. J Rheumatol. 2002;29:2245-6.

22. Taysi S, Polat F, Gul M. Lipid peroxidation, some extracellular antioxidants, and antioxidant enzymes in serum of patients with rheumatoid arthritis. Rheumatol Int. 2002;21:200-4.

23. Cimen MY, Cimen OB, Kacmaz M, Ozturk HS, Yorgancioglu R, Durak I. Oxidant/antioxidant status of the erythrocytes from patients with rheumatoid arthritis. Clin Rheumatol. 2000;19:275-77.

24. Kose K, Yazici C, Cambay N, Ascioglu O, Dogan P. Lipid peroxidation and erythrocyte antioxidant enzymes in patients with Behçet's disease. Tohoku J Exp Med. 2002; 197:9-16.

25. Aydin E, Sogut S, Ozyurt H, Ozugurlu F, Akyol A. Comparison of serum nitric oxide, malondialdehyde levels, and antioxidant enzyme activities in Behçet's disease with and without ocular disease. Ophthalmic Res. 2004; 36:177-82.

26. Saglam K, Serce AF, Yilmaz MI. Trace elements and antioxidant enzymes in Behçet's disease. Rheumatol Int. 2002; 22:93-6.

27. Schulz HU, Niederau C, Klonowski-Stumpe H, Halangk W, Luthen R, Lippert H. Oxidative stress in acute pancreatitis. Hepatogastroenterology. 1999; 46:273650.

28.Karaguezyan KG, Haroutjunian VM, Mamiconyan RS, Hakobian GS, Nazaretian EE, Hovsepyan LM, et al. Evidence of oxidative stress in erythrocyte phospholipid composition in the pathogenesis of familial Mediterranean fever (periodical disease). Clin Pathol. 1996; 49:453-5.

29. Sarkisian T, Emerit I, Arutyunyan R, Levy A, Cernjavski L, Filipe P. Familial Mediterranean fever: clastogenic plasma factors correlated with increased O2(-) production by neutrophils. Hum Genet. 1997; 101:23842.

30. Kirkali G, Tunca M, Genc S, Jaruga P, Dizdaroglu M. Oxidative DNA damage in polymorphonuclear leukocytes of patients with familial Mediterranean fever. Free Radic Biol Med. 2008; 44:386-93.

31. Comporti M. Glutathione depleting agents and lipid peroxidation. Chem Phys Lipids. 1987; 45:143-9.

32. Freeman BA, Crapo JD. Biology of disease: Free radicals and tissue injury. Lab Invest. 1982; 47:412-26.

33. Dalle-Donne I, Rossi R, Colombo R, Giustarini D, Milzani A. Biomarkers of oxidative damage in human disease. Clin Chem. 2006; 52:601-23. 
34. Seven A, Güzel S, Aslan M, Hamuryudan V. Lipid, protein, DNA oxidation and antioxidant status in rheumatoid arthritis. Clin Biochem. 2008; 41:53843.

35. Gambhir JK, Lali P, Jain AK. Correlation between blood antioxidant levels and lipid peroxidation in rheumatoid arthritis. Clin Biochem. 1997; 30:351-55.

36. Kiziltunc AC, Ogalgil Ss Cerrahoglu L. Carnithine and antioxidants levels in patients with rheumatoid arthritis. Scand J Rheumatol. 1998;27:441-5.

37. Sandicki R, Türkmen S, Güvenen G, Ayabakan H, Gülcan P, Koldas M, et al. Lipid peroxidation and antioxidant defence system in patients with active or inactive Behçet's disease. Acta Dermatol Venereol. 2003;83:342-6.

38. Buldanlioglu S, Türkmen S, Ayabakan HB, Yenice N, Vardar M, Dogan S, et al. Nitric oxide, lipid peroxidation and antioxidant defence system in patients with active or inactive Behçet's disease. $\mathrm{BrJ}$ Dermatol. 2005; 153:526-30.

39. Dincer Y, Alademir Z, Hamuryudan V, Fresko I, Akcay T. Superoxide dismutase activity and glutathione system in erythrocytes of men with Behcet's disease. Tohoku J Exp Med. 2002; 198:191-5.

40. Sarban S, Kocyigit A, Yazar M, Isikan UE. Plasma total antioxidant capacity, lipid peroxidation, and erythrocyte antioxidant enzyme activities in patients with rheumatoid arthritis and osteoarthritis. Clin Biochem. 2005; 38:981-6.

41. Hassan MQ, Hadi RA, Al-Rawi ZS, Padron VA, Stohs SJ. The glutathione defense system in the pathogenesis of rheumatoid arthritis. J Appl Toxicol. 2001; 21:6973.

42. Karatas F, Ozates I, Canatan H, Halifeoglu I, Karatepe M, Colakt R. Antioxidant status\&lipid peroxidation in patients with rheumatoid arthritis. Indian J Med Res. 2003; 118:178-81.

43. Vasanthi P, Ganesan N, Hariprasad C, Rajasekhar G, Meera S. Plasma lipophilic antioxidant and prooxidant levels in rheumatoid arthritis. I Indian Rheumatol Assoc. 2004; 12:40-2.

44. Gurbuz M, Yamanel L, Bulucu F, Inal V, Aydin A. Oxidative stress status in familial Mediterranean fever with or without proteinuria. Free Radic Biol Med. 2005; 38:271-5.

45. Burton W, Inglod KU. Beta carotene: an unusual type of lipid antioxidant. Science. 1984; 224:569-73.

46. Comstock GW, Burke AE, Hoffman SC. Serum concentrations of alpha tocopherol, beta carotene, and retinol preceding the diagnosis of rheumatoid arthritis and systemic lupus erythematosus. Ann Rheum Dis. 1997; 56:323-5.

47. Singh U, Devaraj S, Jialal I. Vitamin E, oxidative stress, and inflammation. Annu Rev Nutr. 2005; 25:151-74.

48. Heliovaara M, Knekt P, Aho K. Serum antioxidants and risk of rheumatoid arthritis. Ann Rheum Dis. 1994; 53:51-3.

49. Venkatraman JT, Chu WC. Effects of dietary omega-3 and omega- 6 lipids and vitamin E on serum cytokines, lipid mediators and anti-DNA antibodies in a mouse model for rheumatoid arthritis. J Am CollNutr. 1999; 18:602-13.

50. Sahin M, Uðuz AC, Demirkan H, Nazýroðlu M. Colchicine modulates oxidative stress in serum and leucocytes from remission patients with Family Mediterranean Fever through regulation of $\mathrm{Ca}^{2}+$ release and the antioxidant system. J Membr Biol. 2011; 240:55-62. 